\title{
EXPLAINING FISH CONSUMPTION BEHAVIOR IN SRI-LANKA: THE ROLE OF CONSIDERATION SET SIZE, ATTITUDE, KNOWLEDGE, CON- VENIENCE ORIENTATION, PRICE CONSCIOUSNESS, AND VARIETY SEEKING TENDENCY
}

\author{
Pethiyagoda $\mathrm{NA}^{1 *}$ and Olsen $\mathrm{SO}^{2}$ \\ ${ }^{1}$ Department of Animal Science, Faculty of Agriculture, University of Ruhuna, Mapalana, Sri Lanka \\ ${ }^{2}$ The Norwegian Business School, University of Tromso, Norway
}

Accepted: 1 August 2012

\begin{abstract}
This study focuses on how and why consumers vary, know and consider different kind of alternatives of fish in their diet. Consideration set size of fish is considered to be affected by consumer attitude, convenience orientation, knowledge, variety seeking tendency and price consciousness in Sri-Lankan context. Thus, it was to investigate how these variables affect the formation of consideration set size. The questionnaire survey was carried out in Galle district in Sri-Lanka with 250 respondents. The confirmatory factor analysis and structural equation modeling in Amos 16.0 were used as statistical analysis tool. It was found that significant positive relationship between consideration set size and fish consumption frequency. Further, this study has found significant positive relationships between knowledge and consideration set size, between variety seeking tendency, variety seeking related to food and between convenience orientation and consideration set size. Further, price consciousness related to food has a negative significant impact on consideration set size. Food marketers should advocate that consumers consider many kind of fish species to increase their consumption of fish. Set size increases through the consumer knowledge variable. Thus, manufacturer can educate the consumers with new spices and meals to increase their consideration set size as a marketing strategy.
\end{abstract}

Key words: Consideration set size, attitude, convenience orientation, knowledge, variety seeking tendency, price consciousness, fish consumption

\section{INTRODUCTION}

Variety is an important factor in food consumption and consumer try to balance their diet throughout the day (breakfast, lunch and dinner) and across meals over a time span (Meiselman 2000). Before deciding what to have for a meal on a particular day, consumers consider the different kind dimensions such as convenience, price, brand, nutrient, health etc. The mental cost of making a choice among alternatives can be exhausting (Laroche et al. 2003). In order to reduce the cognitive effort and negative feelings associated with choice, consumers use heuristics or situational goals to form a set of alternatives that apply to the situation (Desai and Hoyer 2000). The key point is that consumers' will make their final choice among the alternatives in their "consideration set size", which is defined as the number of alternatives retrieved from memory or provoked by external cues at a particular choice occasion (Nedungadi 1990).

\footnotetext{
*Corresponding author: niyomipethiyagoda@yahoo.com
}

Branding theory argues that wide range of alternatives within a brand category helps the brand to a bigger market share (Swaminathan et al. 2001), as well as a bigger share of the consumer's consideration set. The size or relative size that the brand category occupies in a person's consideration set is therefore of importance for the likelihood of the given brand to be choosen. Hence in this study, it is argued that the same arguments should hold true for considering alternatives within a product category such as food/fish which is considered as the product category for this study.

Consideration set size is considered to be affected by many factors in consumer behavior studies. Attitudes or preference are among some of the most important factors for explaining human behavior and consumer choices in general included fish consumption (Rortveit and Olsen 2009). Since the consideration set is a part of a person's memory structure (Alba and Chattopadhyay 1985), it is reasonable to 


\section{PETHIYAGODA AND OLSEN: FISH CONSUMPTION BEHAVIOR IN SRI LANKA}

anticipate that knowledge effects the formation of consideration set. Buckley et al. (2007) showed that changing lifestyles lead to increase demand for convenience foods. Thus, identification of the degree to which consumers strive for convenience is useful to understanding consumer behavior towards fish products in combination with consideration set size in particular (Rortveit and Olsen 2009). Variety is a normal part of food choice behaviour (McAlister and Pessemiern 1982), and may be caused by a general personality trait of the consumer or internal causes such as the individual's intrinsic need for variety which is called as variety seeking tendency related to variety (ibid). Price consciousness may impact consumers' consideration sets because price conscious individuals only consider products that are cheaper than their competitors (Hayley 2005).

Most of the relevant studies in examining the food / seafood consumption behavior based on the context of either European or American countries. A little work had been done in the context of Asia as well as other developing countries (Tuu et al. 2008). To date, there appear to be no published studies have been investigated how the consideration set size of a food product category, in this case fish, and influences the consumption of fish in SriLanka. Thus, this study explored the relationship among attitude, knowledge, convenience orientation, price consciousness, variety seeking tendency and consideration set size to understand the consumer's fish consumption pattern in the context of Sri-Lanka.

Conceptual Framework and theoretical foundation: The relationships proposed between the concepts are placed in a theoretical framework related to each constructs are addressed in Figure 1.

The research assumptions of this study have built on the past studies (Rortveit and Olsen 2007: 2009) in according to better understand-

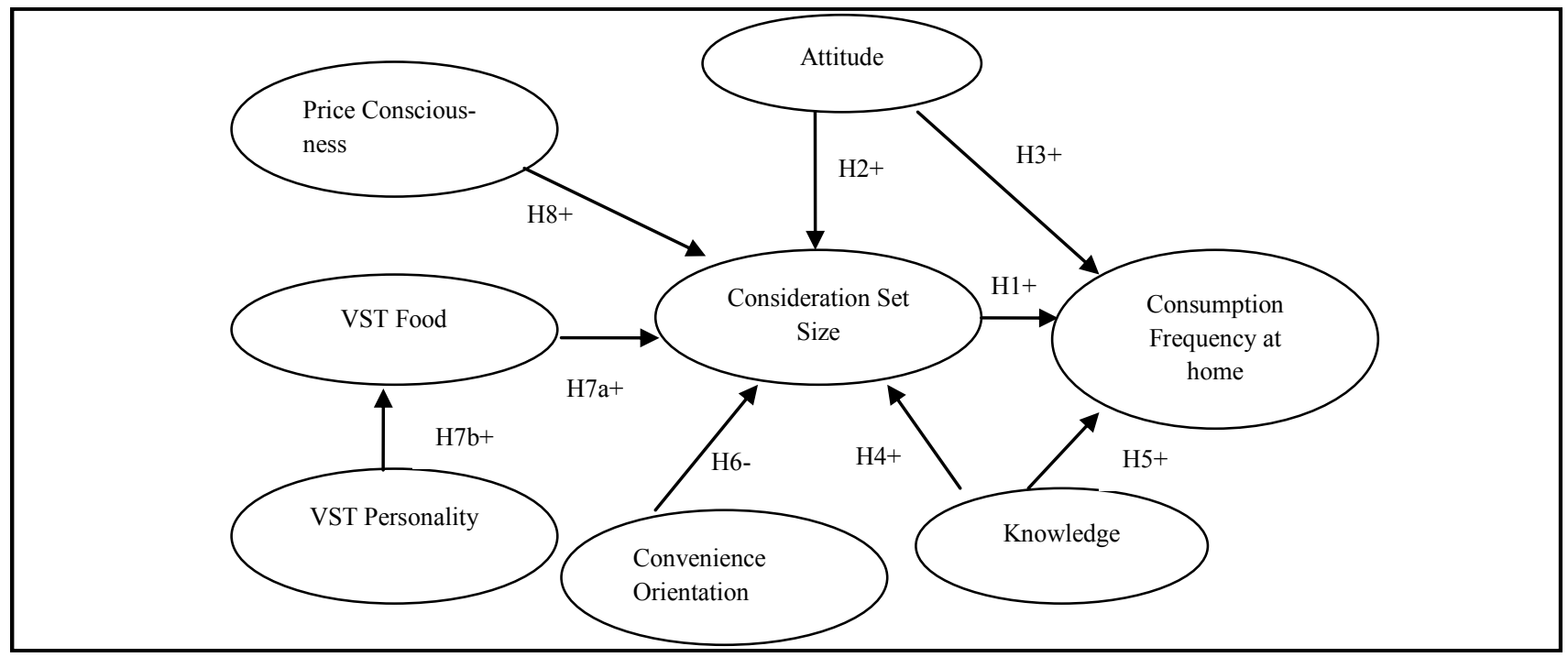

Figure 1: The proposed conceptual model

H1. Consideration set size has a positive effect on the consumption frequency of fish

H2: Attitudes toward fish are positively related to consideration set size

H3: Attitudes toward fish are positively related to consumption frequency of fish

H4: Knowledge is positively related to a consideration set size

H5: Knowledge is positively related to consumption frequency of fish

H6: Convenience orientation has a direct negative effect on consideration set size

H7a): Variety seeking tendency towards food has a positive effect on consideration set size

H7 b) Variety seeking tendency as a general personally trait is positive related to variety seeking tendency related to food

H8: Price consciousness individuals have a direct positive effect on consideration set size 
ing of relationships among main constructs which affect for consideration set size such as attitude (Paulssen and Bagozzi 2005), knowledge (Alba and Chattopadhyay 1985), convenience (Olsen et al. 2007), variety seeking (Van Trijp and Steenkamp 1992), and price consciousness (Lichtenstein et al. 1993). Overall, the formation of the consideration set and how it relates to consumption is the main purpose of this study. Even though it is possible to argue about different direct effects between all variables in this conceptual framework, my focus is mostly limited to argue for some of those effects.

\section{MATERIALS AND METHODS}

Sample and procedure: The consumer survey was conducted in five cities in Galle District. Data were collected by personally delivering the final questionnaire to the respondents at their residence or work place and then collected it later at agreed upon time. A convenience sample of 250 respondents was selected purposively and 207 of usable questionnaires were obtained from the survey. The majority of the respondents in the sample were female (84\%) as in most families, foods are prepared by the female in the context of Sri- Lanka. Average age among the respondents was 33 years while almost all the respondents $(82.2 \%)$ in the sample were less than or at the middle age (45 years). Furthermore, 73 percent respondents were married and the average house hold size was 4.6 persons. The mean family income of the sample was 17500 rupees per month $(1 \mathrm{USD}=110$ Rupees). More respondents of the sample $(81.3 \%)$ have education level more than high school.

Measurement of constructs: Consideration set size was measured by three items on a 10 point numeric scale. Measuring the consideration set, the situational context was primed with following sentence: "Thinking about buying and preparing a meal (lunch) of fish in the last month..." The respondents then had to indicate on a numerical scale. The items were: "How many species (carp, anchovy, mackerel, pike, tuna...etc) would you usually consider?", "How many conservation forms (fresh, frozen, dried, canned, salted fish...etc) would you normally consider?", "How many ways of preparing a meal (cooked, fried, grilled, soup, steamed...etc) would you usually consider?" These items had been used in many prior studies of Rortveit and Olsen (2007, 2009)

It was assessed the participant's attitudes towards fish using items on 7- point semantic differential formats. The participants were asked to rate "how you feel when you eat fish as a meal" on five 7-point semantic differential scales with bipolar adjectives varying from 1 (bad/ unsatisfied/ unpleasant/ dull/ negative) to 7 (good/ satisfied/ unpleasant/ exiting/ positive) (Frewer et al. 1994; Olsen 2003)

Product knowledge was measured subjectively with different items, where the respondents self-evaluated their knowledge on a 7 point Likert scale ranging from "totally disagree" to "totally agree". The ten items measuring knowledge are: "Compared to an average person, I know a lot about fish", "I know a lot of different spices of fish", "My friends consider me an expert on fish", "I have a lot of knowledge about how to evaluate the quality of fish", The items reflect general product class knowledge about fish and are consistent with measures used in prior research (Brucks 1985; Park et al. 1994; Verbeke and Vackier 2005).

Convenience orientation was measured using following items: "I prefer meals that are easy to plan, buy (provide), prepare and cook", "The less physical effort (work, energy) I need to plan, buy, prepare/cook a meal, the better", "I want to spend as little time as possible on planning, buying, and preparing/ cooking of what to have for meals", and "It is waste of time to spend a long time in planning, buying, preparing and cooking meal" 
and "I want to spend as little time as possible on meal preparation". These items were measured on a seven-point Likert scale ranging from (1) ("totally disagree") to (7) ("totally agree"). These items were consisted with previous researches as Candel (2001).

Variety-seeking tendency related to food was measured by items on a seven-point Likert scale ranging from "Totally disagree" (1) to "Totally agree" (7). The items were: "Food items on the menu that I am unfamiliar with make me curious", "I find myself eating many of the same foods day after day", "Most people do not eat as many different foods as I do", "I do not usually change the food in my diet much from day to day", "My diet is higher in variety than most people I know", and "I vary with food, but only with few kinds of food". These items were adopted by the VERSEEK scale (Van Trijp and Steenkamp 1992).

Variety-seeking tendency related to personality trait was measured by items on a sevenpoint Likert scale ranging from "Totally disagree" (1) to "Totally agree" (7). The items were: "I like to experience novelty and change in my daily routine", "I like a job that offers change, variety and travel, even if it involves some danger", "I am continually seeking new ideas and experiences", "I like continually changing activities", Above items were adopted by the original scale of Change Seeker Index (CSI). Furthermore, these items have been used in several previous researches such as Candel (2001) and Van Trijp and Steenkamp (1992).

Price consciousness related to food was measured by these items: "When buying food items, I look for the cheapest", "When it comes to buy food items, I rely heavily on Price", "When buying food items, I consider price first", "The lower price food types are usually my choice", "I will shop at more than one store to take advantages of low priced food items", "These items were measured on a seven-point Likert scale ranging from (1) ("totally disagree") to (7) ("totally agree). These items were consistent with previous researches Lichtenstein, Netemeyer, and Burton (1990).

To assess consumption frequency of fish, this study first used two items to assess the content in order to reduce measurement biases or survey errors (Sudaman, Bradburn and Schwarz 1996): general frequency and recent frequency in line with previous studies. The general frequency measures of behaviour used a one-year time framework and were addressed by nine-point scale of the form "How many times-on average-during the last year have you eaten the fish at home or out of your home" ranging from Daily or almost every day (1) to Never (9) (Raats, Shepherd, and Sparks 1995). Recent frequency was assessed by 15 -point scale of the form "Can you estimate how many times during last week you have eaten fish for every main meal in your home or out of your home'": $0,1,2, \ldots, 14$ times or more. This scale has also been previously used to assess the consumption frequency of seafood (Olsen et al. 2005).

Analytical procedures: These analyses were conducted using maximum likelihood estimation in Amos 16.0. A number of indexes were used to assess overall model fit (measurements and construct model) as the Chi-square $(\chi 2)$, Goodness of Fit Index (GFI), Comparative Fit Index (CFI), and Root mean square error of approximation (RMSEA).

\section{RESULTS}

Confirmatory factor analysis and validation of measures: Confirmatory factor analysis of the eight latent constructs was performed to determine the constructs' convergent and discriminate qualities. Initially, an exploratory factor analysis was done in order to identify the most appropriate items for each constructs. Then a first confirmatory analysis proved several modifications, which result in modifications until the final solution. The fac- 
tor analysis confirmed that 21 items resulted in measurement model reflecting the theoretical constructs in a close fit with a $\chi^{2}-$ value of $186.391(\mathrm{df}=144, \mathrm{p}=.01)$; RMSEA $=.038 ; \mathrm{GFI}=.921 ; \mathrm{CFI}=.960$. The factor loadings (lambdas- $\lambda$ ) were ranged from 0.51 to 0.88 with $\mathrm{t}$ value from 7.95 to 14.36 , were all significant $(\mathrm{p}<.01)$ (Table 4.1$)$, confirming that all items in the measurement model reflect the theoretical constructs as expected. This satisfied the criteria for convergent validity for the eight internal constructs.

The measure of close fit RMSEA (0.038) for the measurement model was below the critical value of 0.05 . The other goodness of fit measures, GFI $=0.921$; $\mathrm{CFI}=0.960$ also showed acceptable value of above 0.90. Composite reliability should be greater than or equal to 0.60 and variance extracted should be greater than or equal to 0.50 . In this study, all composite reliability measures were above 0.6 and variance extracted was above 0.5 , but except the variance extracted value of the construct of convenience orientation which is 0.42 (Table 1). However, the study chooses to keep the convenience orientation value in the model since it has shown to have an influence on food choice in earlier studies. The standardized confirmatory factor analysis co-efficient and construct reliability for the measurement model are presented in Table 1.

The measures of attitude, convenience orientation, knowledge, variety seeking tendency, price consciousness, consideration set size and consumption frequency were tested to prove discriminant validity. Discriminant validity exists if the average variance extracted from two constructs is higher than the square of the correlation between the two constructs (Bagozzi Li and Phillips 1991).

\section{Structural analysis of the model testing:} The $\chi^{2}$ for the model was 198.946 with 153 degrees of freedom $(p=0.007)$. The appropriate measure of model fit in data with a large sample size is RMSEA. The measure of close fit RMSEA (0.038) was within the recommended level of 0.05 (Browne and Cudeck 1992). GFI and CFI are 0.921 and 0.949, respectively and clearly exceed the recommended level of 0.9 (Bollen 1989).

First, the structural model analysis support the main hypothesis that set size has a positive effect on consumption frequency of fish. The path co-efficient of $.33(\mathrm{t}=.5 .001 ; \mathrm{p}<.000)$ gives support for $\mathrm{H} 1$, and means that more fish alternatives the consumer considered, the more likely it is that a member of the product category fish is chosen.

The path coefficient of 0.03 ( $\mathrm{t}=.383$; ns) does not lead to accept that H2. H3 was concerned with the effect of attitude on consideration set size. Even there was a positive relationship between attitude and consideration set size as expected, the effect was non significant ( $\beta$ $=.10, \mathrm{t}=1.283, \mathrm{~ns})$. Therefore both hypothesis $\mathrm{H} 2$ and $\mathrm{H} 3$ was not supported.

As mentioned in H4, this study further expected that Knowledge is positively related to consideration set size. These results lead to accept that $\mathrm{H} 4$ which explains the positive relationship between knowledge and consideration set size $(\beta=.16, \mathrm{t}=2.02, \mathrm{p}$ $<.05)$.Further these results showed that the relationship between knowledge and the fish consumption frequency (H5) was insignificant $(\beta=.09, \mathrm{t}=1.119, \mathrm{~ns})$. The results of H6 revealed the significant positive impact with path co-efficient of $.30(t=3.09 ; p<.01)$ between convenience orientation and consideration set size. This result does not lead to accept that $\mathrm{H} 6$

H7 (a) was proposed concerning the positive relationship between variety seeking tendency related food and consideration set size but the result found non significant $(\beta=.02, \mathrm{t}=.305$, ns), not supporting for $\mathrm{H} 7 \mathrm{a}$. As mentioned in $\mathrm{H} 7$ (b), the result of this study indicated that variety seeking tendency related to personality was significantly positively related to con- 
Table 1: Standardized confirmatory factor analysis coefficients and construct reliability

\begin{tabular}{|c|c|c|c|}
\hline \multirow[t]{2}{*}{ Constructs and indicators } & \multicolumn{2}{|c|}{ St. factor Composite } & \multirow{2}{*}{$\begin{array}{l}\text { Varianc } \\
\text { Extracte }\end{array}$} \\
\hline & & & \\
\hline Attitude & & 0.71 & $\mathbf{0 . 5 0}$ \\
\hline Satisfied/Unsatisfied & .66 & & \\
\hline Pleasant/Unpleasant & .70 & & \\
\hline Positive/ Negative & 67 & & \\
\hline Convenience orientation & & 0.67 & 0.42 \\
\hline The less physical effort (work, energy) I need to plan, buy, prepare/cook a meal, the better & .51 & & \\
\hline $\begin{array}{l}\text { I want to spend as little time as possible on planning, buying, and preparing/cooking of what to have } \\
\text { for meals }\end{array}$ & .81 & & \\
\hline It is waste of time to spend a long time in planning, buying, preparing and cooking meal & .59 & & \\
\hline Knowledge & & 0.84 & 0.64 \\
\hline I know a lot of different spices of fish & .86 & & \\
\hline Compared to an average person, I know a lot about fish & .83 & & \\
\hline My friends consider me an expert on fish & .71 & & \\
\hline $\begin{array}{l}\text { Variety seeking tendency } \\
\text { ( related to food) }\end{array}$ & & 0.63 & 0.55 \\
\hline Food items on the menu that I am unfamiliar with make me curious & .74 & & \\
\hline I do not usually change the food in my diet much from day to day & .88 & & \\
\hline $\begin{array}{l}\text { Variety seeking tendency } \\
\text { as a personality trait }\end{array}$ & & $\mathbf{0 . 8 0}$ & 0.51 \\
\hline I like to experience novelty and change in my daily routine & .68 & & \\
\hline I like a job that offers change, variety and travel, even if it involves some danger & .57 & & \\
\hline I am continually seeking new ideas and experiences & .78 & & \\
\hline I like continually changing activities & .79 & & \\
\hline Price consciousness ( related to food) & & 0.73 & 0.50 \\
\hline When buying food items, I look for the cheapest & .59 & & \\
\hline When buying food items, I consider price first & .76 & & \\
\hline I will shop at more than one store to take advantages of low priced food items & .71 & & \\
\hline Consideration set size & & 1.00 & 1.00 \\
\hline
\end{tabular}

How many different fish species you usually consider in buying and preparing a meal in the last 1.00 month?

Fish consumption frequency

Could you please estimate how many times during last 14 days you have eaten fish for the lunch at 1.00 home?

Note: Chi - Square $=186.391, \mathrm{df}=144, \mathrm{p}$-value $=.01 ; \mathrm{RMSEA}=.038 ; \mathrm{GFI}=.921 ; \mathrm{CFI}=.960, \mathrm{~N}=207$.

The correlations between the factors proposed in the model are listed in below.

Table 2: Construct means, standard deviation and correlation of the constructs

\begin{tabular}{|c|c|c|c|c|c|c|c|c|c|c|}
\hline & Mean & SD & 1 & 2 & 3 & 4 & 5 & 6 & 7 & 8 \\
\hline 1. Attitude & 5.89 & .88 & 1.0 & & & & & & & \\
\hline 2.Con. orientation & 5.65 & 1.15 & -.08 & 1.0 & & & & & & \\
\hline 3.Knowledge & 3.24 & 1.56 & .01 & $.15^{*}$ & 1.0 & & & & & \\
\hline 4.VST Food & 5.00 & 1.59 & $.17^{*}$ & -.10 & -.01 & 1.0 & & & & \\
\hline 5.VST Person & 4.95 & 1.32 & $.15^{*}$ & .02 & .02 & $.22 * *$ & 1.0 & & & \\
\hline 6. P. consciousness & 3.72 & 1.52 & .08 & $.17 *$ & $.34 * *$ & -.15 & .11 & 1.0 & & \\
\hline 7.Consideration set & 5.00 & 1.78 & $.07 *$ & $.25^{* *}$ & $.13 * *$ & .03 & .02 & $-.11 *$ & 1.0 & \\
\hline 8. F. Consumption & 5.00 & 1.99 & -.05 & $.34 *$ & $.13^{*}$ & .13 & .06 & .02 & $.34 * *$ & 1.0 \\
\hline
\end{tabular}

Note: ${ }^{*} \mathrm{p}<.1{ }^{* *} \mathrm{p}<.01 ; * * \mathrm{p}<.000$, Chi - Square $=186.391, \mathrm{df}=144, \mathrm{p}$-value $=.01 ;$ RMSEA $=.038 ; \mathrm{GFI}=.921 ; \mathrm{CFI}=.960, \mathrm{~N}$ $=207$, ns: nonsignificant 
sideration set size $(\beta=.22, \mathrm{t}=2.160, \mathrm{p}<.05)$, thereby H7 (b) was supported.

H8 was proposed concerning the positive relationship between the price consciousness and the consideration set size. Even there was a significant relationship resulted, it was negative $(\beta=-.22, \mathrm{t}=-2.423, \mathrm{p}<.05)$, not supporting H8. Finally, the final model explained 12.5 percent of the variance in consideration set size $(\mathrm{R} 2=.125)$ and 12.5 percent of the variance in fish consumption frequency ( $\mathrm{R} 2$ $=.125)$.

\section{DISCUSSION \& CONCLUSION}

An important goal of this study was to determine the extent to which the consideration set size affects fish consumption frequency. In the context of this study, It was found significant positive relationship between consideration set size and the fish consumption frequency $(\beta=.33, \mathrm{t}=5.001, \mathrm{p}<.000)$. This relationship has been shown in early studies, confirming that a brand or product needs to be a part of consideration set to be chosen (Desai and Hoyer 2000; Nedungadi 1990; Priester et al. 2004). Adopting this within food choices, in the light of the theoretical arguments and empirical findings, Rortveit and Olsen (2007) and Olsen et al. (2007) have also shown that consideration set size is positively related to the consumption frequency of fish.

Several studies confirmed strong positive effect between attitude towards eating fish and consumption frequency of fish (Olsen 1999; Olsen 2003, Olsen et al. 2007; Tuu et al. 2008). However, it was found in this study that general attitude was statistically insignificant towards fish consumption frequency in Sri-Lanka. It may explain that because almost all people like fish as a food in the study area (attitudes are positively skewed), it fails to provide much of the variability in the relationship between attitude and consumption frequency of fish.

The relationship between attitude and consideration set has to my knowledge only been investigated in three studies. Paulssen and Bagozzi (2005) found that desired benefits, as a facet of attitude and more specific goals, determined brand consideration of cars while Rovert and Olsen (2009) and Olsen et al. (2007) further emphasized that consideration set size is positively related to consumption frequency of the fish in the context of Europe. However, in this study the relationship between attitude and consideration set was insignificant, may be due to most of consumers like fish have a small impact of considering fish alternatives in buying and consuming for main meal (choice occasion).

The result lead to accept the positive relationship between knowledge and consideration set size. This result is analogous with several studies (Alba and Chattopadhyay 1985; Aurier et al. 2000) which shows knowledge within a product category has a positive impact on likelihood of an alternative from this particular product category being chosen (Crities and Aikman 2005). In case of this study, product category familiarity knowledge have impact on consideration set size formation which is in line with previous study of Aurier et al. (2000) which showed how familiarity with usage context affects the consideration set size. This finding is supported by the study which familiarity knowledge in case of fish has an impact on the alternatives of fish considering in buying and consuming occasions in the context of Sri-Lanka.

This study further emphasized that the relationship between knowledge and consumption frequency was insignificant. But contrary to expectation and previous research findings, positive significant relationship was found between knowledge and the consumption frequency in other studies (Ajzen 1991; Armitage and Conner, 2001).In this study, it may explain that fish consumers do not consider product knowledge in the consumption occasions as most of them are seemed to be familiar and know about fish. Most of the respondents (about 85\%) in the sample are elders, 
thereby they may think that they are expert in knowledge in terms of familiarity of fish (know lot of fish species). It may fail to provide much of the variability in the relationship between knowledge and consumption frequency of fish.

This Research is compatible with the idea of that convenience orientation has an important effect on consumer's buying decisions and food choice (Candel 2001). Rorveit and Olsen (2009) and Olsen et al. (2007) have explored the relationship between convenience orientation and fish consumption through a consideration set size and found there is a direct negative relationship between convenience orientation and the consideration set size. In this study it is argued if the consumer is more convenience orientated; it will lead to smaller consideration, thereby convenience orientation has a negative influence of consideration set size. Even though this study has confirmed positive significant relationship among those constructs which is lined with the study of Kim Anh (2010) who discovered a positive relationship between convenience orientation and the consideration set size. It may explain if the consumers are more convenience orientated regarding preparing meal, they will consider for more fish alternatives which can be easily cooked without consuming much more time. Same time, now in Sri-Lankan culture, most of women engage in busy life may also a big factor for searching more alternatives within food category when they are buying and preparing the meal at home.

It is argued that variety-seeking tendency related to food of consumers will have an impact on fish alternatives which are part of the consideration or choice set of consumers, but this study found the effect is insignificant, Thus, it is confirmed even though there is a consumer's intrinsic desire for variation of food, it has negligible effect on the number of fish alternatives considered when they buy and consume fish. This may explain that consumers may seek more food variation, but it doesn't necessary explain that these consumers must consider more fish alternatives as to satisfy their variation of food, thereby they can consider for more other alternatives to satisfy their needs and protein requirements of their meals.

This study tested the relationship between the general variety seeking tendency as a personality trait and the more specific variety seeking tendency related to food. The result led to accept the significantly positive relationship between variety seeking tendency related to food and variety seeking related to personality. From the theory (Van Trijp 1995), the consumers high in this personality trait feel positive to variation of food. Thus, a general variation tendency (personality) should influence more on specific variation tendency (food) (ibid). It may explain the consumers who seek variation in their general life tend to vary in foods as well.

The relationship between price consciousness related to food and the consideration set size has formed concerning the significant positive effect (Dawson 2003), this study has ended up with the significant negative relationship between price consciousness related to food and the consideration set size. It may explain the consumers who are price conscious, searching for lower price foods do not consider many fish alternatives (large consideration set). This is consistent with prior research of Dawson (2003) who showed that price consciousness individuals would have small consideration sets as they consider small sets. My logical explain is that, consumer in SriLankan context consider few alternatives of fish when buying and consuming occasions as fish is comparatively high priced food.

The managerial implications of this study are several. The study has shown that number of fish species considered on choice occasion has a significant impact on consumption frequency of fish. It creates opportunities for marketing people as they can expand fish 
market share by providing different fish species to market. In the context of generic promotion is common, marketing strategy should approach consumer education towards seeking variety in order to increase their industry share of the food market. The findings of this study also indicate that set size can be increased through the knowledge variable. In such a condition, manufacturer must tend to put in to consumer education which will lead to have a positive impact on consideration set size.

One important finding in this study is the evidence that consumers are more convenience orientated, there by marketers can introduce more products related to food, including fish as an instant products which can be easily cooked and saved as a meal. As this survey included most of the women, these convenience products can be promoted among them as they mainly engage in the cooking and preparing meals in the home stage. Furthermore, marketers should consider the elements of manufactured goods such as: product size, preservability, packaging and design, which can reduce consumers' time and effort in purchasing, storage, and use, have been related to convenience orientation. As Sri-Lanka is a developing country, consumers tend to buy lower price food products as they are more concern about the economic situation in their families. Many households find fresh and high quality fish are expensive buy cheaper alternatives of frozen and processed products, such as fish fingers. Therefore, marketers can adopt for a supply lower price products to the market in order to meet the needs of consumers.

\section{REFERENCES}

Ajzen I 1991 The theory of planned behaviorOrganizational behavior and human decision Processes. Journal of Consumer Research, 50: 179-211.

Alba JW and Chattopadhyay A 1985 Effects of context and part-category cues on recall of competing brands. Journal of Marketing Research, 22(3): 340-49.

Armitage CJ and Conner M 2001 Efficacy of the theory of planned behavior: a meta-analytic review. British Journal of Social Psychology, 40: 471-499.

Aurier P, Jean S and Zaichkowsky JL 2000 Consideration set size and familiarity with usage context. Advances in Consumer Research, 27 (27): 307-313.

Brucks M 1985 The effects of product class knowledge on information search behaviour. Journal of Consumer Research, 12(1): 1-16.

Candel MJJM 2001 Consumers' convenience orientation towards meal preparation: Conceptualization and measurement. Appetite, 36 (1): 15-28.

Crites SL and Aikman SN 2005 Impact of nutrition knowledge on food evaluations. European Journal of Clinical Nutrition, 59: 1191-1200.

Dawson HL 2003 Factor confirmation and construct validation of a brand loyalty scale. Master's thesis, Southern Illinois University Carbondale.

Desai KK and Hoyer WD 2000 Descriptive characteristics of memory-based consideration sets: influence of usage occasion frequency and usage location familiarity. Journal of Consumer Research, 27( 3): 309-323.

Frewer LJ, Shepherd R and Sparks P 1994 The interrelationships between perceived knowledge, control and risk associated with a range of food-related hazards targeted at the individual, other people and society. Journal of Food Safety, 14: 19-40.

Hayley LD 2005 Doctor of Philosophy Degree in Applied Psychology, Southern Illinois University Carbondale.

Kim Anh NT 2010 The role of consumer satisfaction, consideration set size, variety seeking and convenience orientation in explaining seafood consumption in Vietnam. Master thesis, University of Tromso, Norway.

Laroche M, Pons F, Zgolli N, Cervello MC and Kim C 2003 A model of consumer response to two retail sales promotion techniques. Journal of Business research, 56(7): 512-522

Lichtenstein DR, Netemeyer RD and Burton S 1990 Distinguishing coupon proneness from value consciousness: an acquisitiontransaction utility theory perspective. Journal of Marketing, 54: 54-67. 
Lichtenstein DR, Ridgway NM and Netemeyer RG 1993 Price perceptions and consumer shopping behavior: a field study. Journal of Marketing Research, 30: 234-245.

McAlister L and Pessemier EA 1982 Variety seeking behavior: An interdisciplinary review. Journal of Consumer Research, 9: 311-322.

Meiselman HL 2000 The effects of variety and monotony on food acceptance and intake at a midday meal. Physiology and behavior, 70 (12): 119-125.

Nedungadi P 1990 Recall and consumer consideration sets: Influencing choice without altering brand evaluations. Journal of Consumer Research, 17(3): 263-276.

Olsen SO 2007 Repurchase loyalty: the role of involvement and satisfaction. Psychology and Marketing, 24(4): 1-28.

Olsen SO 2003 Understanding the relationship between age and seafood consumption: the mediating role of attitude, health involvement and convenience. Food Quality and Preference, 14: $199-209$.

Olsen SO, Wilcox J and Olsson U 2005 Consequences of ambivalence on satisfaction and loyalty. Psychology and Marketing, 22: 24768.

Park CW, Mothersbaugh DL and Feick L 1994 Consumer knowledge assessment. Journal of Consumer Research, 21(1) :71-82.

Paulssen M and Bagozzi RP 2005 A selfregulatory model of consideration set formation. Psychology and Marketing, 22(10): 785 -812 .
Priester JR, Nayakankuppam D, Fleming MA and Godek J 2004 The A(2)SC(2) model: the influence of attitudes and attitude strength on consideration and choice. Journal of Consumer Research, 30(4) : 574-587.

Rortveit AW and Olsen SO 2009 Combining the role of convenience and consideration set size in explaining fish consumption in Norway. Appetite, 52: 313-317.

Rortveit AW and Olsen SO 2007 The role of consideration set size in explaining fish consumption. Appetite, 49(1): 214-222.

Swaminathan V, Fox RJ and Reddy SK 2001 The impact of brand extension introduction on choice. Journal of Marketing, 65(4): 1-15.

Tuu HH, Olsen SO, Thao DT and Kim Anh NT 2008 The role of norms in explaining attitudes, intention and consumption of a common food (fish) in Vietnam. Appetite, 51: 546-551.

Van Trijp HCM 1995 Variety seeking in product choice behaviour: theory with applications in the food domain. Mansholt Studies 1 Wageningen Agricultural University: 209.

Van Trijp HCM and Steenkamp JBEM 1992 Consumers' variety seeking tendency with respect to foods: measurement and managerial implications. European Review of Agricultural Economics, 19: 181-195.

Verbeke W and Vackier I 2005 Individual determinants of fish consumption: application of the theory of planned behavior. Appetite, 44: $67-82$. 